\title{
Os retornados chineses da América Latina em Macau
}

\author{
Bi Meng Yin ${ }^{1}$
}

Resumo: Há um grupo pequeno e específico em Macau que são os retornados chineses da América Latina. Como há poucos materiais sobre eles, o estudo vai ajudar a entender a posição histórica de Macau durante a imigração chinesa na América Latina. Através do trabalho, também poderemos conhecer a vida dos chineses em Macau. A partir da observação de aspetos sociais, humanos e linguísticos indicaremos algumas das suas características únicas.

Palavras-chave: imigração chinesa na América Latina; interação; retornados em Macau.

\section{Introdução:}

Por causa da História, Macau tem uma ligação forte com Portugal e uma posição como ponte entre a China e os países de Língua Portuguesa. No entanto, em Macau também há uma grande diversidade de nacionalidades. Mas é sempre ignorado um grupo que possui uma identidade especial na região, que são os retornados chineses da América do sul, o tema desse artigo.

Os sujeitos da nossa pesquisa são emigrantes chineses que moraram muito anos fora ou nasceram nos países da América do sul, e agora eles voltaram e moram em Macau. O fenômeno mostra além dos aspetos humanos, sociais também questões de língua. Por isso é um tema significativo para investigar.

O trabalho vai tratar principalmente de duas partes. A primeira é sobre a história dos emigrantes chineses. Antes de 1979, quando foi lançada a política de reforma e da abertura, a China era um país muito fechado, existiam várias limitações para emigrar; por outro lado, no mundo também faltava um comunicação mais global. A segunda parte vai apresentar a análise das entrevistas com os retornados. As perguntas da entrevista são sobre a saída da China, a vida no país sul-americano, o retorno e a vida em Macau.

Através do trabalho, conheceremos primeiro a história da emigração chinesa, o fenómeno de coolies e também a saga dos retornados em Macau. Com a análise dos dados, conheceremos mais realidades sobre os retornados.

\footnotetext{
1 Pesquisadora do Grupo de Pesquisa CNPq-USP Mudança Gramatical do Português Gramaticalização, da FFCLRP/USP. Bolsista CNPq de mestrado. E-mail: alicechinesa@gmail.com. Este texto é um recorte da monografia de graduação Os retornados chineses da América Latina em Macau (2011), desenvolvida no Departamento de Português da Universidade de Macau e orientada pelo Professor Doutor Roberval Teixeira e Silva.
} 


\section{A história da emigração chinesa}

Os emigrantes do final do século XIX tinham duas características:

Primeiro, como uma grande quantidade de trabalhadores chineses foi contratada para trabalhar em países estrangeiros, houve um aumento significativo de chineses fora da China; eles se repartiram por todo o mundo. Em geral, antes do final da dinastia Qing, os chineses saíam da China para procurar um melhor ambiente econômico, mas a quantidade era limitada e se concentrava no sul da Ásia. Mas no final da dinastia Qing, a quantidade de chineses no exterior aumentou em milhões, e se dividiram pela América do Norte e do Sul, África e Austrália.

A segunda característica é o desenvolvimento do poder económico dos chineses no exterior. Através do esforço de gerações, até o final do século XIX essas comunidades chinesas passaram a ter condições económicas relativamente boas.

Um fenómeno típico na imigração chinesa são os coolies. No início do século XIX, os países ocidentais revogaram sucessivamente os tratados de escravidão, entretanto havia ainda muito trabalho como a plantação de cana e açúcar em Cuba, a mineração e a coleta de guano no Peru, etc. Essas atividades precisavam de bastantes trabalhadores. Como a China na época era economicamente mais fraca, os europeus vieram à China procurar os coolies chineses para substituir os escravos africanos. Os coolies eram principalmente camponeses e os pescadores das regiões litorais do sul da China. Segundo as estatísticas (1963), desde 1800 até 1925, três milhões coolies foram transportados para estrangeiro.

Macau foi um centro dos negócios de coolies por mais de 20 anos. Em 1871, Cuba e outros países da América Latina estabeleceram cinco gabinetes de representação para organizar os negócios em Macau. Os coolies foram chamados migrantes voluntários para evitar as opiniões públicas internacionais. Entre os portos de migração na China, Macau foi o único lugar onde os negócios de coolies foram organizados e orientados pelo seu governo. Como afirma Oneill (2012), diz o professor Huang Hongzhao, da Universidade de Nanjing, que:

O governo de Macau ganhou muito dinheiro através de negócios. Depois do estabalecimento de Hong Kong in 1842, a economia de Macau foi declinando. Macau precisou de um novo setor para a sua economia, e os negócios com os coolies foi um deles. 
Os imigrantes, no início, foram contratados para trabalhar em mercados, ganhando pouco salário para sobreviver. Depois, eles escolheram fazer negócios pequenos.

\section{A situação dos retornados em Macau}

Macau é uma cidade internacional com muitas culturas. Os retornados vieram de todo o mundo, de contextos culturais muito diferentes e convivem com outros povos aqui em Macau. Devido à sua importância, desde 2008, há a Associação de Juventude Chineses Ultramarinos Retornados de Macau.

Já não conseguimos definir quando começaram a vir os retornados chineses do estrangeiro. Os retornados vieram para Macau normalmente não por causa da guerra. Eles vieram primeiro porque Macau fica ao lado da China Continental. Por causa da política, os retornados tinham medo de voltar para a China Continental, mas como eles tinham saudades da pátria, escolheram voltar para Macau. Uma outra razão para o retorno foi que Macau é uma sociedade chinesa, e assim o nível da vida não era muito alto. Uma terceira razão foi que os processos de imigração para Macau não eram tão complicados como para outros países, e não havia muitos requerimentos de finança e garantia. Por estas razões, muitos emigrantes idosos retornaram para passar o seu tempo aqui, muitos voltaram com as suas famílias, e também muitos mandaram os seus filhos para estudar o chinês e a cultura chinesa em Macau para não se esquecerem de seu sangue chinês.

Através de narrações das duas entrevistadas, que são duas jovens de cerca de 22 anos, retornadas do Brasil e da Venezuela. Vamos observar aqui apenas os motivos que levaram à saída e depois ao retorno.

Sobre a saída, a Maria, da Venezuela, conta-nos:

Os meus pais moraram cerca de 30 anos na Venezuela. Eles moraram em Valência, uma cidade pequena perto da capital Estado Carabobo Caracas, escolheram aquela cidade porque não havia muita concorrência, mas também havia uma vida comparativamente fácil. Nos anos 80 na China, depois da Revolução da Cultura e no inico da reforma e abertura, a vida do povo em geral, especialmente nas cidades interiores, era muito díficil. A população estava muito pobre e não tinha oportunidades de ganhar dinheiro. Como Enping (terra natal dos pais da família da Maria, fica na provincia Cantão) não é muito longe do mar, muitas pessoas de lá saíram para o estrangeiro, uma grande parte foi para a América Latina. Porque naquela época, muitos países lá estavam em regime de ditatura, a sociedade era mais segura e era também mais fácil eles ganharem dinheiro. Como o meu pai tinha um parente na Venezuela, ele foi lá e depois conheceu a minha mãe. A minha família abriu uma loja que vendia produtos domésticos, brinquedos, etc. 
A busca por uma vida melhor e a insegurança em relação às políticas da China são as motivações que a Maria destaca. Os emigrantes não foram coletivamente, foram sozinhos ou com a sua própria família.

Sobre o retorno, a Teresa, que veio do Brasil, conta-nos:

A minha mãe disse que seria melhor voltar para a China, para conhecer mais sobre a China. Porque quem sabe chinês e português no Brasil, o emprego já está garantido, né. Queria ir estudar a Pequim, a capital. Mas foi difícil ir diretamente lá, porque não a minha família não conbeceu nada sobre lá. Por isso fui primeiro a Singapora estudar a Gestão, da qual não gostei. Como os meus avós são de Macau, mudei finalmente para a Macau.

O reencontro com as raízes, as perspectivas do futuro são motivações para o retorno, segundo o discurso dessa jovem.

O processo de retorno não foi fácil. A Teresa acha que é muito dificil fazer amizade com as pessoas locais, mesmo que ela tenha a face chinesa e fale cantonês, o qual ela acha que não é totalmente igual ao dos colegas de Macau; acha que a mente dela é diferente do que pensam os colegas chineses.

Retornar a viver em Macau depois tantos anos de morar fora também é uma escolha cheia de coragem e considerações. O objetivo comum delas ao regressar é ter mais contato com a cultura e língua chinesa. De fato, é mais difícil para os retornados chineses a adaptação à vida em Macau, porque, se fossem estrangeiros com a face muito diferente da dos chineses (por exemplo a pele branca com cabelo loiro), as pessoas locais entenderiam melhor que eles são de fora. Mas como tem a face igual à das pessoas locais, eles sofrem porque os locais os avaliam com mais exigências.

\section{Conclusão}

A imigração chinesa tem uma longa história, mas em grande escala começou na Dinastia Qing, por causa, por exemplo, do aparecimento do fenómeno de coolies. Milhões de chineses foram transportados para os países ocidentais, especialmente para a América Latina.

Em Macau, encontram-se várias culturas diferentes, os retornados chineses da América Latina estão separados na população. Através das duas entrevistas com as duas jovens retornadas da América Latina, podemos observar que elas vivem uma situação singular. Elas têm as suas vantagens, tais como a de falarem outras línguas e a de terem tido experiências diferentes dos locais. Por outro lado, elas também enfrentam as dificuldades por causa das culturas diferentes, porque não é tão fácil, para elas, integrarem-se na comunidade chinesa. 


\section{Referências}

MEAGHER, Arnold J. The Coolie trade: the traffic in Chinese laborers to Latin America1847-1874. United States: Xlibris Corporation and Hardcover, 2008.

NARVAEZ, Benjamin Nicolas. Chinese Coolies in Cuba and Peru: Race, Labor, and Immigration, 1839-1886. Dissertation of doctor. Austin: University of Texas at Austin, 2010.

ONEILL, Mark. Humans as Commodity. Macao Magazine. Disponível em: $<$ http://www.macaomagazine.net/index.php?option=com_content\&view=art icle\&id=129: humans-as-commodity\&catid=41:issue-6>.$\quad$ Acesso em: 24.set.2012.

广东省政协文史资料研究委员会《华侨沧桑录》,

广东:广东人民出版社, 1984。[Associação de Pesquisa Histórica da Província de Guangdong. Hua Qiao Cang Sang Lu (Relatórios dos Imigrantes Chineses). Guangdong: Editor do Povo de Guangdong, 1984].

庄国土《中国封建政府的华侨政策》厦门:厦门大学出版社, 1989。[Z HUANG, Guotu. Zhong Guo Feng Jian Zheng Fu de Hua Qiao Zhen Ce (Políticas de imigração do governo feudal da China. Xia Men: Editor de Universidade de Xiamen, 1989.]

陈泽宪《十九世纪盛行的契约华工制》, 载《历史研究》1963年第一 期. [CHEN Zexian. Shi Jiu Shi Ji Sheng Xing De Qi Yue Hua Gong Zhi (Mecanismo de trabalhadores chineses no século XIX.) Pesquisa histórica, 1963.]

許均銓，林清風《歸僑在澳門》澳門:華人國際新聞出版集團出版， 2005。 [XU Junquan, LIN Qingfeng. Gui Qiao Zai Ao Men (Os retornados em Macau). Macau: China News International Publishing Group, 2005.]

鄭妙冰《澳門 : 殖民滄桑中的文化雙面神》香港 : 明報出版社, 2004。[ZHENG Miaobing. Ao Men: Zhi Ming Cang Sang Zhong De Wen Hua Shuang Mian Shen (Macau: Lugar de duas culturas na história de colonização). Hong Kong: Ming Pao Daily Press, 2004.] 